\title{
Behavioural disturbance after intravenous ketamine infusion for treatment of refractory chronic pain
}

\author{
Hemkumar Pushparaj, MBBS, MD • Anuj Bhatia, MBBS, \\ MD, FRCA, FRCPC, FIPP, FFPMRCA, EDRA, CIPS, ASRA-PMUC
}

Received: 27 December 2019/Revised: 29 February 2020/Accepted: 4 March 2020/Published online: 17 March 2020

(C) Canadian Anesthesiologists' Society 2020

\section{To the Editor,}

While there has been a dramatic increase in the use of intravenous ketamine infusion for treating refractory chronic pain, ${ }^{1}$ the interaction of ketamine with other medications may have unpredictable consequences. With written informed consent, we describe a patient showing severe behavioural disturbance following ketamine infusion therapy and resumption of cannabinoid intake.

The subject was a 44-yr-old male with persistent (18 months) severe post-surgical neuropathic pain at multiple upper extremity sites. He experienced a workplace-related injury leading to right scapholunate instability requiring two operations. During physiotherapy, he sustained a left scaphoid dislocation with distal biceps tear that also required surgery. The pain was most severe on his right forearm (Numerical Pain Rating Scale score 8/10) with a neuropathic character (Douleur Neuropathique score 7/10, Neuropathic Pain Symptom Inventory score 53/100). Less

H. Pushparaj, MBBS, MD

Department of Anesthesia, Faculty of Medicine, University of Toronto, Toronto, ON, Canada

Department of Anesthesia and Pain Medicine, Toronto Western Hospital, Toronto, ON, Canada

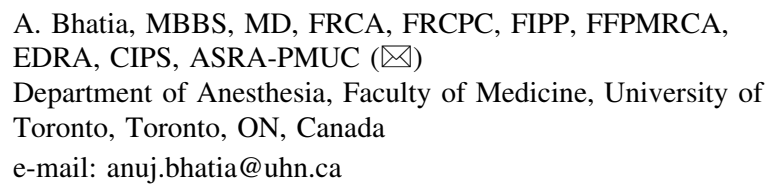

Department of Anesthesia and Pain Medicine, Toronto Western Hospital, Toronto, ON, Canada

Institute of Health Policy Management and Evaluation, University of Toronto, Toronto, ON, Canada pain was also present over the surgical scars on his left elbow and forearm. Previous treatment included gabapentinoids and opioids, but these had been stopped because of adverse effects. Pain medications when presenting to our clinic included duloxetine, amitriptyline, zopiclone, temazepam, vaporized cannabidiol (CBD) oil, and delta-9-tetrahydrocannabinol (THC), $0.3 \mathrm{~g} \cdot$ week $^{-1}$. There was no history of personal or familial mental health disorders. Physical examination revealed hypoesthesia to light touch and pinprick, and temporal summation of pain at the scar sites. He was offered a high-dose intravenous ketamine infusion program (30 hr over five days; 8:00 am to 2:00 pm each day) in a monitored setting at our hospital.

The patient stopped cannabinoid use $24 \mathrm{hr}$ before beginning the ketamine infusion program. Ketamine infusion was initiated with a bolus of $0.5 \mathrm{mg} \cdot \mathrm{kg}^{-1}$ followed by $0.5 \mathrm{mg} \cdot \mathrm{kg}^{-1} \cdot \mathrm{hr}^{-1}$ and titrated to a maximum of $1.6 \mathrm{mg} \cdot \mathrm{kg}^{-1} \cdot \mathrm{hr}^{-1}$ by the end of the second day. Intravenous midazolam, ondansetron, and dexamethasone were administered daily, before ketamine, to help prevent adverse effects. Magnesium sulfate $\left(50 \mathrm{mg} \cdot \mathrm{kg}^{-1}\right.$ bolus followed by an infusion of $\left.15 \mathrm{mg} \cdot \mathrm{kg}^{-1} \cdot \mathrm{hr}^{-1}\right)$ and lidocaine $\left(5 \mathrm{mg} \cdot \mathrm{kg}^{-1}\right)$ were added on the third, fourth, and fifth days to improve pain relief. No adverse neurologic, psychologic, or cardiovascular effects were observed during treatment.

The patient re-initiated vaporized THC use (two-three times his usual dose) on the evening of the last day of the infusion because pain relief was insufficient. Approximately $24 \mathrm{hr}$ later, his wife observed him to be restless, agitated, and aggressive, and he was brought to a hospital emergency room $48 \mathrm{hr}$ following the last ketamine infusion. A urine drug screen was positive for ketamine, benzodiazepines, and zopiclone but negative for opioids, amphetamine, and cocaine. He was admitted to the 
Psychiatric Intensive Care Unit where his behaviour was judged to be agitated, hypersexual, confused, and disinhibited. Physical and pharmacological (intramuscular loxapine and lorazepam) restraints were required. His symptoms resolved over the next four days and was diagnosed with a behavioural disturbance syndrome likely due to ketamine and cannabinoids. Confounding effects of duloxetine, amitriptyline, benzodiazepines and zopiclone couldn't be ruled out. The patient did not exhibit further behavioural disturbances and was doing well six months after discharge.

Affective switch to mania after ketamine infusion for treatment-resistant depression has been previously reported. $^{2}$ Ketamine can also cause mood switch in patients with bipolar disorders, but has not been associated with manic symptoms in otherwise euthymic patients. ${ }^{1}$ Though exposure to cannabinoids can be associated with psychotic episodes in adolescents and vulnerable young adults, ${ }^{3}$ cannabinoids have not been associated with persistent psychotic disorders. Considering the known psychomimetic effects of ketamine, we believe the drug was likely responsible for inducing psychosis in our patient while cannabinoids potentiated the psychotic episode. Interestingly, THC and $\mathrm{CBD}$, the major psychoactive components of marijuana, are primarily metabolised by CYP2C9 and 3A4 enzymes. ${ }^{4}$ Ketamine can inhibit CYP3A4 gene expression thus reducing activity of this enzyme ${ }^{5}$ and elevating THC and CBD levels. Such elevated levels would be especially marked in our patient who increased his vaporized THC consumption following the ketamine infusion program. This report illustrates the unpredictable behavioural effects of ketamine and other medications. In particular, we would caution against the concomitant administration of high-dose ketamine and cannabinoids.

\section{Conflicts of interest None.}

Funding statement This work was supported by internal departmental funding from the Department of Anesthesia and Pain Medicine at University Health Network - Toronto Western Hospital.

Editorial responsibility This submission was handled by Dr. Steven Backman, Associate Editor, Canadian Journal of Anesthesia.

\section{References}

1. Cohen SP, Bhatia A, Buvanendran A, et al. Consensus guidelines on the use of intravenous ketamine infusions for chronic pain from the American Society of Regional Anesthesia and Pain Medicine, the American Academy of Pain Medicine, and the American Society of Anesthesiologists. Reg Anesth Pain Med 2018; 43: 52146.

2. McInnes LA, James-Myers MB, Turner MS. Possible affective switch associated with intravenous ketamine treatment in a patient with bipolar I disorder. Biol Psychiatry 2016; 79: e71-2.

3. Deng H, Verrico CD, Kosten TR, Nielsen DA. Psychosis and synthetic cannabinoids. Psychiatry Res 2018; 268: 400-12.

4. Stout SM, Cimino NM. Exogenous cannabinoids as substrates, inhibitors, and inducers of human drug metabolizing enzymes: a systematic review. Drug Metab Rev 2014; 46: 86-95.

5. Chen JT, Chen RM. Mechanisms of ketamine-involved regulation of cytochrome P450 gene expression. Expert Opin Drug Metab Toxicol 2010; 6: 273-81.

Publisher's Note Springer Nature remains neutral with regard to jurisdictional claims in published maps and institutional affiliations. 